\title{
Utilité de la LC-MS/MS dans les agressions sexuelles sous l'emprise de molécules psychoactives. Étude d'un cas impliquant du zolpidem
}

\section{Usefulness of LC-MS/MS in drug-facilitated sexual assault evidence. A case study involving zolpidem}

\section{Pascal KINTZ*(1), Marion VILLAIN(1), Véronique DUMESTRE-TOULET ${ }^{(2)}$, Vincent CIRIMELEE ${ }^{(1)}$}

(1) Laboratoire ChemTox, 3, rue Gruninger, F-67400 Illkirch - France (2) Laboratoire ToxGen, Bordeaux - France

*Corresponding Author: Pascal KINTZ, Laboratoire ChemTox, 3, rue Gruninger, F-67400 Illkirch - France Tel : +33 390400540 - Fax : +33 390400451 - E-mail : pkintz@labochemtox.com

(Reçu le 7 novembre 2005 ; accepté le 17 décembre 2005)

\section{RÉSUMÉ}

L'utilisation de drogues pour modifier le comportement d'une personne dans le but de lui faire de la rendre vulnérable n'est pas un phénomène récent. Cependant, l'augmentation récente du nombre de crimes (agression sexuelle, vol) où la victime est sous l'emprise de molécules psychoactives fait peur au public. Les drogues impliquées peuvent être de types pharmaceutiques comme les benzodiazépines (flunitrazepam, lorazepam, etc), les hypnotiques (zopiclone, zolpidem), les sédatifs (neuroleptiques, certains antagonistes $H I$ de l'histamine) ou les anesthésiants (gamma-hydroxybutyrate, kétamine), des stupéfiants comme le cannabis, l'ecstasy ou le lysergide ou plus souvent de l'éthanol.

Les drogues utilisées pour faciliter les agressions sexuelles peuvent être difficiles à détecter (produits actifs à faible concentration, instabilité chimique) car elles possèdent des propriétés amnésiantes et sont rapidement éliminés du corps

\section{SUMMARY}

The use of a drug to modify a person's behavior for criminal gain is not a recent phenomenon. However, the recent increase in reports of drug-facilitated crimes (sexual assault, robbery) has caused alarm in the general public. Drugs involved can be pharmaceuticals, such as benzodiazepines (flunitrazepam, lorazepam etc), hypnotics (zopiclone, zolpidem), sedatives (neuroleptics, some histamine HI-antagonists) or anaesthetics (gamma-hydroxybutyrate, ketamine), drugs of abuse, such as cannabis, ecstasy or lysergide, or more often ethanol.

Drugs used to facilitate sexual assaults can be difficult to detect (active products at low dosages, chemical instability), possess amnesic properties and can be rapidly cleared from the body (short half-life).

We present here a case involving a 23-year old girl that declared a sexual assault 6 days after the event should have 
(deni-vie courte).

Nous présentons ici le cas d'une femme de 23 ans qui a déclaré avoir été violée, 6 jours après la date présumée de l'agression. A la police, la victime prétend n'avoir aucun souvenir de l'agression, en raison d'une sédation intense. Des analyses toxicologiques pour rechercher des drogues sédatives inconnues ont été menées par LC-MS/MS et ont révélé la présence de zolpidem (Stilnox), un hypnotique qui n'est pas une benzodiazépine. Les concentrations après 6 jours étaient respectivement de 16 et $32 \mathrm{pg} / \mathrm{ml}$ dans le sang et les urines. La substance incriminée avait une concentration de $0,75 \mathrm{pg} / \mathrm{mg}$ dans le segment de cheveux correspondant.

La sensibilité extraordinaire du couplage LC-MS/MS apparâtt comme un pré-requis pour documenter les cas de crines sous influence de molécules psychoactives.

\section{Introduction}

The use of a drug to modify a person's behavior for criminal gain is not a recent phenomenon. However, the sudden increase in reports of drug-facilitated crimes (sexual assaults, robbery...) has caused alarm in the general public. Drugs involved can be pharmaceuticals, such as benzodiazepines (flunitrazepam, lorazepam...), hypnotics (zopiclone, zolpidem), sedatives (neuroleptics, some histamine $\mathrm{H} 1$-antagonists), anesthetics (gamma hydroxybutyrate or GHB, ketamine), drugs of abuse (cannabis, ecstasy, LSD), or more often ethanol. Most of these substances possess amnesic properties and therefore the victims are less able to accurately recall the circumstances under which the sexual offence occurred. As they are generally short acting, they impair an individual rapidly. Due to their low dosage, excepted for GHB, a surreptitious administration into beverages such as coffee, soft drinks (cola) or even better alcoholic cocktails is relatively simple (1).

To perform successful toxicological examinations, the analyst must follow some important rules: $1 /$ to obtain as soon as possible the corresponding biological specimens (blood, urine and hair), 2/ to use sophisticated analytical techniques (LC/MS, headspace/GC/MS, tandem mass spectrometry); and 3/ to take care on the interpretation of the findings. To address this problem, guidelines for toxicological investigations were published in both the United States of America (2) and France (3).

Urinalysis of drug use in cases of alleged sexual assault demonstrated in 3303 urine samples that ethanol, either alone or in combination with other drugs, was the most common substance found, followed by cannabis and benzodiazepines (4). In Paris, the largest study conducted in France(5) revealed that most frequently used drugs were benzodiazepines and related hypnotics. GHB was very seldom found. In our series at Strasbourg (3), zolpidem appears as the commonest substance, followed by bromazepam. occurred. To the Police, the victim claimed a total amnesia of the offense associated to intense sedation. Toxicological analyses for unknown sedative drugs achieved by LCMS/MS revealed the presence of zolpidem (Stilnox), a nonbenzodiazepine hypnotic. Concentrations after 6 days were 16 and $32 \mathrm{pg} / \mathrm{ml}$ in blood and urine, respectively. The drug tested positive in the corresponding hair segment at $0.75 \mathrm{pg} / \mathrm{mg}$.

The requested extraordinary sensitivity of LC-MS/MS appears as a pre-requisite to document any case involving drug-facilitated crime.

For all compounds involved in drug-facilitated sexual assault (DFSA), the detection times in blood and urine depend mainly on the dose and sensitivity of the method used. Prohibiting immunoassays and using only hyphenated techniques, substances can be found in blood for 6 hours (GHB) to several days (6). In most cases, sampling blood or urine has low interest 48-72 hours after the offense occurred, particularly when the analyses are achieved using liquid chromatography coupled to diode array detection or gas chromatography coupled to mass spectrometry, the standard procedures that are used in most laboratories.

To address a response to this important caveat, hair was suggested as a valuable specimen (8-10). This laboratory recommends waiting for 4-5 weeks after the offense and then collecting 4 strands of about 100 hairs. One strand will be used to test for drugs of abuse (mostly for cannabis, but also for ecstasy related compounds and cocaine that are sometimes observed) and pharmaceuticals, one for GHB by segmentation and the other one for a screening of hypnotics and the last remains for a potential counter-analysis. After decontamination, hair is then segmented as follows: 0 to $2 \mathrm{~cm}$ (segment corresponding to the period of crime), 2 to 4 and 4 to $6 \mathrm{~cm}$ (which should be drug-free).

This paper presents a case of late declaration (after 6 days) of a sexual assault under the influence of zolpidem, where the drug was simultaneously identified in blood, urine and hair by a very sensitive analytical procedure involving LC-MS/MS.

\section{Case report}

A 23-year old girl went to the Police 6 days after an alleged sexual assault. She declared having organized a party at home with relatives, where alcohol was largely used. After a discussion with a man, she lost consciousness, with no recall of the event. The next 
day, she recovered nude in a bed with him. She claimed that her glass was spiked with an unknown drug that made her "different". With no apparent reason, she waited several days before going to the Police.

She was send to a medico-legal unit for both clinical examination and toxicological specimens sampling. The medical doctor did not evidence violence marks. Blood, collected under EDTA and urine, collected without preservatives, were sampled at that time and stored at $+4^{\circ} \mathrm{C}$ until analyses. After discussion with the toxicologist, 2 hair strands (blond hair) were collected 7 weeks after the alleged offense, in the vertex posterior region, and stored at ambient temperature.

\section{Toxicological analyses}

Ethanol, drugs of abuse, and pharmaceuticals including GHB were screened by routine procedures, involving immunoassays (fluorescence polarization immunoassay, Abbott system), liquid chromatography coupled to diode array detection and gas chromatography coupled to mass spectrometry. As it is the case in all drug-facilitated crimes, hypnotics were tested by LC-MS/MS according to a procedure previously described (11).

Briefly, blood or urine $(1 \mathrm{ml})$ were extracted at $\mathrm{pH} 8.4$ ( $1 \mathrm{~mL}$ phosphate buffer), in presence of $10 \mathrm{ng}$ of diazepam- $\mathrm{d}_{5}$ with a mixture of methylene chloride/diethyl ether (80/20). After agitation and centrifugation, the organic phase was evaporated to dryness and the residue was reconstituted in $50 \mu \mathrm{L}$ of acetonitrile/water (50/50). The hair strand was twice decontaminated using methylene chloride ( $5 \mathrm{~mL}, 2 \mathrm{~min}$ ) and then segmented ( 3 segments of $2 \mathrm{~cm}$ ). Each segment was cut into small pieces $(<1 \mathrm{~mm})$. About $20 \mathrm{mg}$ were overnight incubated in $1 \mathrm{~mL}$ of phosphate buffer at $\mathrm{pH} 8.4$, in presence of $1 \mathrm{ng}$ of diazepam- $\mathrm{d}_{5}$ used as internal standard (IS). After a liquid-liquid extraction with $5 \mathrm{~mL}$ of a mixture of methylene chloride/diethyl ether (80/20) and evaporation to dryness, the residue was reconstituted in $50 \mu \mathrm{l}$ of acetonitrile/water (50/50).

LC was performed using a Waters Alliance 2695 system. Chromatography was achieved using a XTerra MS C18 column $(100 \times 2.1 \mathrm{~mm}, 3.5 \mu \mathrm{m})$ eluted with a gradient of acetonitrile and formiate $\mathrm{pH} 3.2$ buffer, delivered at a flow rate of $0.2 \mathrm{~mL} / \mathrm{min}$. An injection volume of $10 \mu \mathrm{L}$ was used in all cases. A Quattro Micro triplequadrupole mass spectrometer (Micromass-Waters) fitted with a Z-Spray ion interface was used for analyses. Ionization was achieved using electrospray in the positive ionization mode (ES+). This screening procedure revealed the presence of zolpidem.

The following conditions were found to be optimal for the analysis of zolpidem and the IS: capillary voltage,
$1.0 \mathrm{kV}$; source block temperature, $120^{\circ} \mathrm{C}$; and desolvatation gas (nitrogen) heated to $350^{\circ} \mathrm{C}$ and delivered at a flow rate of $550 \mathrm{~L} / \mathrm{h}$. In order to establish appropriate multiple reaction monitoring (MRM) conditions, the cone voltage was adjusted to maximize the intensity of the protonated molecular ion and collision induced dissociation (CID) of both species was performed. Molecular ions $(\mathrm{m} / \mathrm{z} 308$ and 290 for zolpidem and the IS, respectively) were selected in Q1 and the corresponding daughter ions ( $\mathrm{m} / \mathrm{z} 235$ and 263 for zolpidem and $\mathrm{m} / \mathrm{z} 154$ and 198 for the IS) were detected in Q3 after collision with argon, used as collision-activated dissociation gas.

\section{Results and discussion}

All the toxicological investigations using conventional procedures were negative or physiological (urinary GHB at $1.3 \mathrm{mg} / \mathrm{L}$ ).

After 6 days of delay between an alleged offense and biological specimens collection, it is not surprising that these analyses were negative, due to metabolic clearance of the drugs from the body. This is the reason why this laboratory recommends in all drug-facilitated sexual assault case to perform the analyses by the most sensitive available technique that is today liquid chromatography coupled to tandem mass spectrometry.

After a screening of the most relevant benzodiazepines and hypnotics, zolpidem was identified in blood (Figure 1) and urine (Figure 2) of the victim. Concentrations were 16 and $32 \mathrm{pg} / \mathrm{ml}$ for blood and urine, respectively. Despite these very low concentrations, zolpidem was identified without any difficulties, by a dual respect of the retention times and the ion ratios criteria. From a controlled excretion study, the urinary zolpidem concentration is consistent with an exposure dating from several days (11).

Hair segmentation confirmed these results (Table I). Positive concentrations were in the $\mathrm{pg} / \mathrm{mg}$ range. Typical chromatograms are given Figures 3 and 4 . Although it is accepted by the scientific community that blond hair (the case of the victim) incorporates less drugs than brown or black hair (12), the observed concentrations are close to that observed after a single drug exposure, i.e. 1.8 to $9.8 \mathrm{pg} / \mathrm{mg}$ (11).

Zolpidem (Stilnox) has been sold in France since 1988. This drug is an imidazopyridine derivative, with a chemical structure unrelated to benzodiazepines. It is intended for once-nightly consumption at a dose of $10 \mathrm{mg}$. Despite its selective interaction with omega-1 receptors, several side effects, including visual disturbance and hallucinations have been described. 
Moreover, impairment of psychomotor performance (13) and effects on recent or remote recall (14) can be both significant.

According to its pharmacological effects, zolpidem can be observed in cases of drug facilitated crimes, including robbery and sexual assault (3). As the drug is short acting (Tmax $=1.7 \mathrm{~h}$ ), it can impair an individual rapidly. Moreover, due to its amnesic properties, the

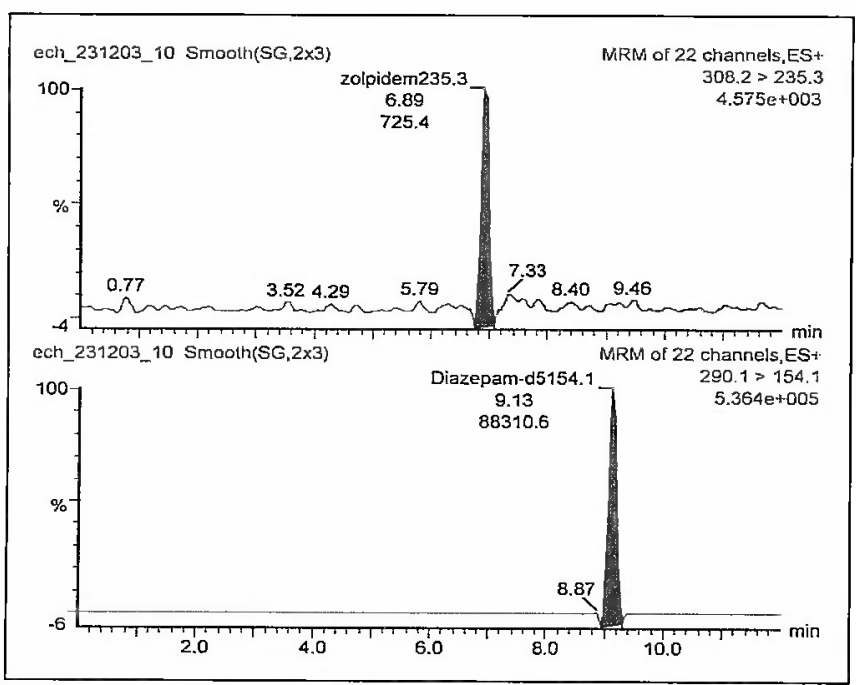

Figure 1 : Chromatogram of the blood extract. Zolpidem concentration is $16 \mathrm{pg} / \mathrm{ml}$. On the top, the daughter ion of zolpidem, on the bottom, the daughter ion of diazepam- $d_{5}$.

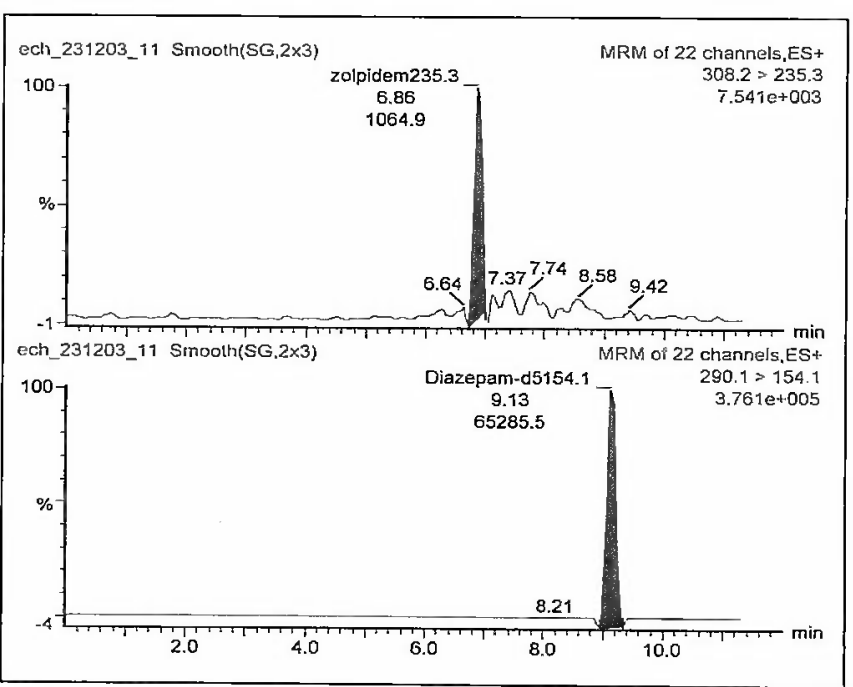

Figure 2 : Chromatogram of the urine extract. Zolpidem concentration is $32 \mathrm{pg} / \mathrm{ml}$. On the top, the daughter ion of zolpidem, on the bottom, the daughter ion of diazepam- $d_{5}$.

Table I: Zolpidem in hair collected 7 weeks after the alleged offense.

\begin{tabular}{|c|c|}
\hline Segment & Zolpidem (pg/mg) \\
\hline 0 (root) $-2 \mathrm{~cm}$ & 0.10 \\
\hline $2-4 \mathrm{~cm}$ & 0.75 \\
\hline $4-6 \mathrm{~cm}$ & not detected \\
\hline
\end{tabular}

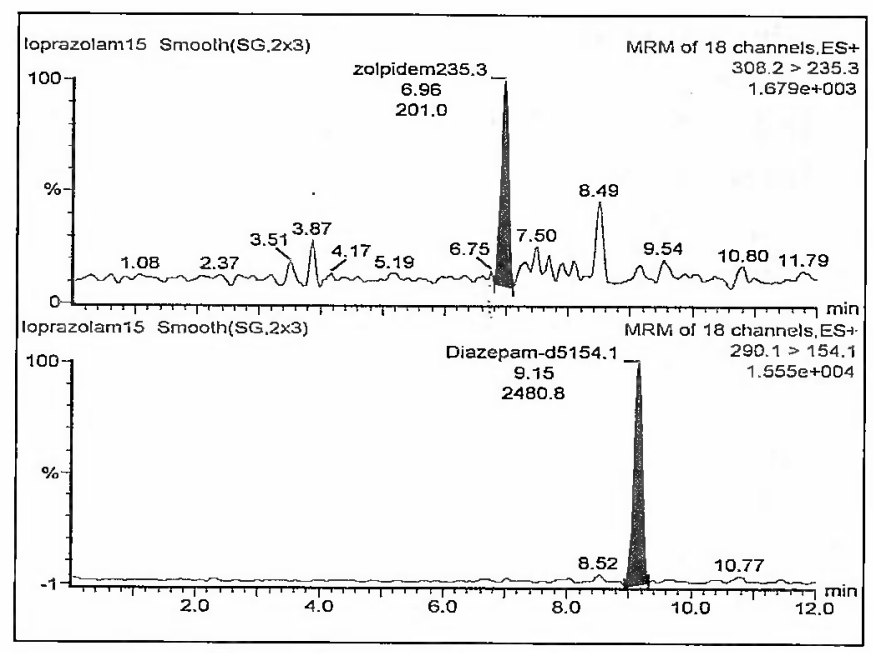

Figure 3 : Chromatogram of a hair extract. Zolpidem concentration is $0.10 \mathrm{pg} / \mathrm{mg}$. On the top, the daughter ion of zolpidem, on the bottom, the daughter ion of diazepam- $d_{5}$.

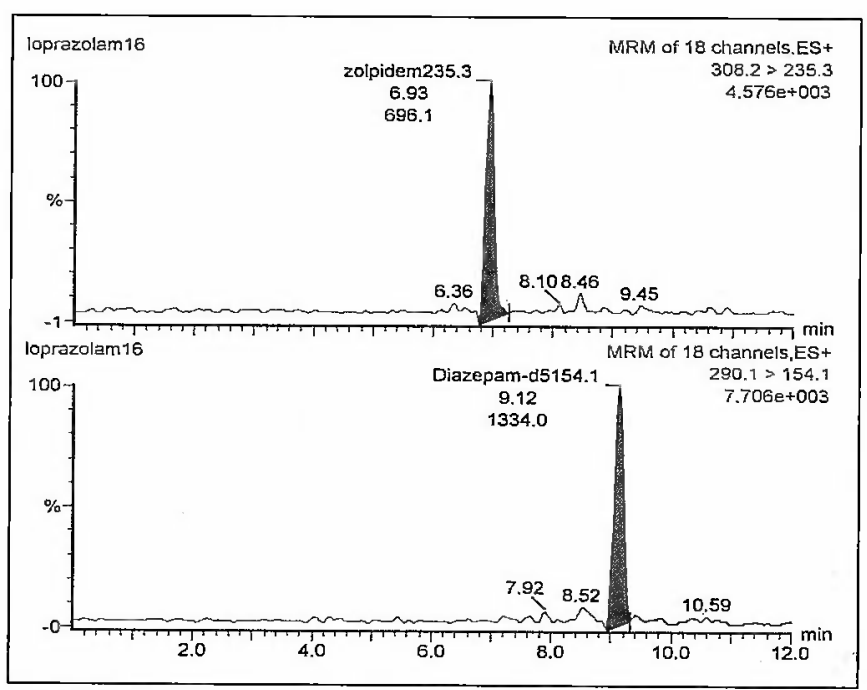

Figure 4 : Chromatogram of a hair extract. Zolpidem. concentration is $0.75 \mathrm{pg} / \mathrm{mg}$. On the top, the daughter ion of zolpidem, on the bottom, the daughter ion of diazepam-d.

victims are less able to accurately recall the circumstances under which the offence occurred.

Despite late sampling, results by LC-MS/MS testing allow to document the use of hypnotics in DFSA. To obtain the requested ultra low limits of detection together with suitable mass spectrometry informations, tandem mass spectrometry appears as a pre-requisite. Selectivity and sensitivity are extraordinarily increased by almost completely suppressing the noise level. In comparison with the concentrations that are measured with drugs of abuse, in case of DFSA, the concentrations are at least 1000 times lower.

As it is the case with 'other applications (survey of addicts, doping control, driving license regranting...) hair testing is a valuable approach to increase the window of drug detection. Embarrassment associated with 
urine collection, particularly after sexual assault, can be greatly mitigated through hair analysis. It is always possible to obtain a fresh, identical hair sample if there is any trouble during analysis, claim of specimen mixup or breach in the chain of custody. This makes hair analysis essentially fail-safe, in contrast to blood or urine analysis, since an identical blood or urine specimen cannot be obtained at a later date. The discrimination between a single exposure and long-term use can be documented by multi-sectional analysis. With the concept of absence of migration along the hair shaft, a single spot of exposure must be present in the segment corresponding to the period of the alleged event, using a growth rate for hair of $1 \mathrm{~cm} / \mathrm{month}$. As this growth rate can vary from 0.7 to $1.4 \mathrm{~cm} / \mathrm{month}$, the length of the hair section must be calculated accordingly. The hair must be cut as close as possible to the scalp. Particular care is also required to ensure that the individual's hair in the strand retains the position it originally had beside one another.
The unique possibility to demonstrate a single drug exposure through hair analysis has some additional interests. In case of late crime declaration, positive hair findings are of paramount importance for a victim, in order to start under suitable conditions a psychological follow-up. These cases are often sensitive with little other forensic evidence. Hair investigation, particularly if segmental analysis is performed, will show longterm ingestion of hypnotics (for therapeutic use) whereas urine will not. The general procedure to collect hair in any drug-facilitated crime is indicated Figure 5.

\section{Conclusion}

In all case involving drug-facilitated sexual assault, selectivity and sensitivity of MS/MS are a pre-requisite. Hair testing should be done in complement of conventional blood and urine analysis as it increases the window of detection and permit to differentiate, by segmentation, a long-term therapeutic use from a single exposure.
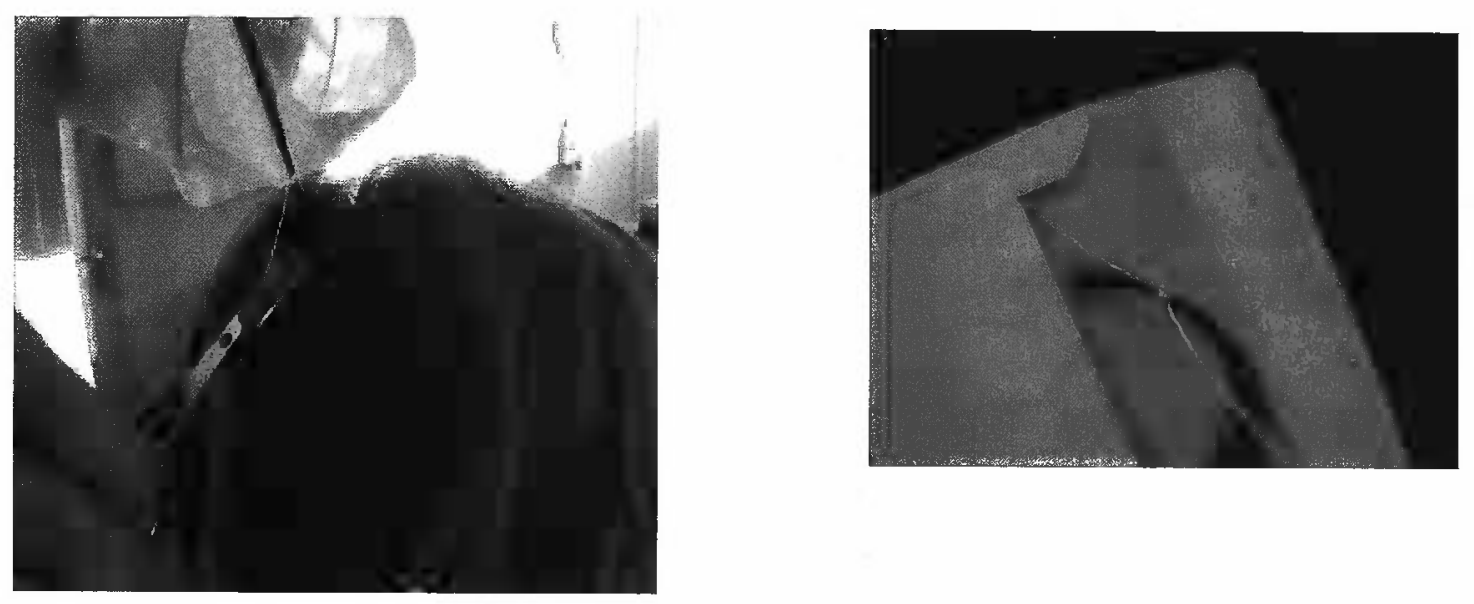

When:

3 to 5 weeks after the alleged event.

How much :

4 strands of hair of about 100 hair.

Where:

in vertex posterior.

How :

- root and tip ends must be distinguished, using a string $1 \mathrm{~cm}$ from the root

- hair must be cut by scissors as close as possible from the scalp

(do not pull out ! do not use adhesive !).

- Storage : in an envelop at ambient temperature.

To be asked to the victim :

- Use of pharmaceuticals before the alleged event?

- Use of pharmaceuticals after the alleged event?

- If yes, which compounds, at which dosage?

- Cosmetic treatments (bleaching, coloration ...) since the alleged event ?

Figure 5 : General procedure to collect hair in a drug-facilitated crime. 


\section{References}

1. D. Wells Drug administration and sexual assault : sex in a glass. Sci and Justice. 41: 197-199 (2001).

2. M. LeBeau, W. Andollo, W.L. Hearn et al. Recommendations for toxicological investigations of drug-facilitated sexual assaults. J. Forensic Sci. 44 : 227 230 (1999).

3. P. Kintz, V. Cirimele, M. Villain, A. Tracqui, and B. Ludes. Soumission chimique : approches pratiques en toxicologie médico-légale. Ann. Toxicol. Anal. 14 : 361 364 (2002).

4. I. Hindmarch, M. ElSohly, J. Gambles, et al. Forensic urinalysis of drug use in cases of alleged sexual assault. J. Clin Forensic Med. 8 : 197-205 (2001).

5. M. Deveaux, M. Chèze, G. Duffort, and G. Pépin. Etude de 128 cas de soumission chimique en région parisienne (juin 2003-mai 2004) : analyses toxicologiques dans les cheveux par chromatographie liquide - spectrométrie de masse en tandem. J. Méd. Lég. Droit Méd. 47 : 351-356 (2004).

6. A. Verstraete. Fenêtre de détection des xénobiotiques dans le sang, les urines, la salive et les cheveux. Ann. Toxicol. Anal. 14 : 390-394 (2002).

7. P. Kintz, V. Cirimele, C. Jamey, and B. Ludes. Testing for GHB in hair by GC-MS/MS after a single exposure. Application to document sexual assault. J. Forensic Sci. $48: 195-200$ (2003).

8. P. Kintz, M. Villain, and B. Ludes. Testing for the undetectable in drug-facilitated sexual assault using hair - analyzed by tandem mass spectrometry-as an evidence. Ther. Drug Monit. $26: 211-214$ (2004).

9. G. Pépin, M. Chèze, G. Duffort, and F. Vaysette. De l'intérêt des cheveux et de la spectrometrie de masse en tandem pour la soumission chimique : à propos de neuf cas. Ann. Toxicol. Anal. 14 : 395-406 (2002).

10. G. Frison, D. Favretto, L. Tedeschi, and S.D. Ferrara Detection of thiopental and pentobarbital in head and pubic hair in a case of drug-facilitated sexual assault. Forensic Sci. Int. 133 : 171-174 (2003).

11. M. Villain, M. Chèze, A. Tracqui, B. Ludes, and P. Kintz. Windows of detection of zolpidem in urine and hair. Application to two drug-facilitated sexual assaults. Forensic Sci. Int., 143 : 157-161 (2004).

12.C. G.L. Henderson, M.R. Harkey, C. Zhou, R.T Jones., and P. Jacob. Incorporation of isotopically labeled cocaine and metabolites into human hair; 1 . Dose response relationships. J. Anal. Toxicol. $20: 1-12$ (1996).

13. B.K. Logan, F.J. Couper. Zolpidem and driving impairment. J. Forensic Sci. 46 : 105-110 (2001).

14. J.P. Goullé, and J.P. Anger. Effets amnésiant des hypnotiques médicamenteux. Revue de la littérature. Cas personnels. Ann. Toxicol. Anal.14 : 381-389 (2002). 